\title{
PDGFRB NP_002600.1:p.T681I
}

National Cancer Institute

\section{Source}

National Cancer Institute. PDGFRB NP 002600.1:p.T6811. NCI Thesaurus. Code

C128174.

A change in the amino acid residue at position 681 in the platelet-derived growth factor receptor beta protein where threonine has been replaced by isoleucine. 